\title{
Gender Differences in the Domain of Job Satisfaction: A Study on the Private Universities of Bangladesh
}

\author{
Ayesha Binte Safiullah', Farhana Rahman Sumi ${ }^{2}$ \\ I (Business Studies, University of Information Technology and Science, Bangladesh) \\ ${ }^{2}$ (Business Studies, University of Information Technology and Science, Bangladesh)
}

\begin{abstract}
Job satisfaction is an elusive and complex concept that has been a focus of intense research since the emergence of organizational studies. Little is known about faculty job satisfaction in higher education sector as well as in the developing countries like Bangladesh. The purpose of this study was to examine the gender differences different domain of job satisfaction and overall satisfaction of academic members in Bangladeshi Private Universities. The study was based on questionnaire method and a sample of 72 academic members from ten private universities of Bangladesh was selected. The data was analyzed using mean values and frequency percentage tables. The result concludes that most academic members were satisfied with their job. Female faculty members were more satisfied than their counterparts. The study also shows some other pivotal factors which have significant contribution in propelling academic members' satisfaction in the educational institutes

Field of study: Human Resource Management.

Keywords: Job satisfaction, factors, Gender differences, Private universities.
\end{abstract}

\section{Introduction}

Teaching is a noble but challenging profession. Teachers' role is extremely important for the development of a society because teacher is one of the pre-requisites for the success of educational programs. Teachers can lead to the success if they are satisfied with the job. There are several factors which is responsible for influencing job satisfaction of any profession. Teaching is not an exception.

Traditionally, only dedicated and selected individuals joined this profession with the noble tendency to develop a society. Although, the role of the teachers in society and in education sector has been changing with the pace of time but the importance of this position is same.

By developing teachers with desirable attitude and by motivating them, effective and productive learning on the part of pupils can be achieved. But the fact is until a teacher derives satisfaction on job performance and develops a positive attitude towards education he or she cannot initiate desirable outcomes to cater to the needs of the society. Only satisfied and well-adjusted teacher can think of the well-being of the pupils.

\subsection{Scope and Objective of the study}

The study has been conducted to analyze and identify the level of Job satisfaction of employees (faculty) as well as to identify whether there is any difference between the level of job satisfaction of male and female employees, who are working in private universities of Bangladesh. For this study, particularly faculties of private universities of Bangladesh have been selected, and as a sample 72 academic members have been taken from ten different private universities.

The objectives of this study are:

1. To analyze the overall job satisfaction of academic members of private universities of Bangladesh.

2. To analyze the job satisfaction level among the male and female teachers.

3. To find out the impact of job satisfaction of teachers on Quality of Education in Bangladesh.

\subsection{Meaning of Job Satisfaction}

\section{Literature Review}

Job satisfaction is one of the most widely discussed notions in the field of Human resource management and organizational behavior. Job satisfaction means a collection of positive feelings that an individual holds toward his or her job (Robbins, 2005) [1]. Someone is satisfied with his job that is job satisfaction. It is like when any job fulfills one's expectation that is job satisfaction.

Job satisfaction can be viewed as "a pleasurable or positive emotional state resulting from the appraisal of one's job experience (Locke, 1976) [2]. Later, Armstrong (2003) defined job satisfaction as the feelings and attitudes of people toward their job. He mentioned that if people have favorable and positive attitudes towards their job, this means job satisfaction, but if they have unfavorable and negative attitudes towards their job, this means job dissatisfaction. [3]. 
Teachers are the ultimate arbiters of educational process. The teacher's satisfaction in his job is extremely important since quality education of the whole nation depends on this. Low job satisfaction is a sign of declining teaching standards. High job satisfaction on the other hand makes work (teaching) well organized. According to Hodson (1991), Job satisfaction can be defined as an individual general attitude towards his or her job [4].

Basically, job satisfaction is all about liking job and finding sense of fulfillment in what a person do. It combines an individual's feelings and emotions about their job and how their job affects their personal lives.

\subsection{Factors Affecting Job Satisfaction}

Paul Spector (1985) defined job satisfaction as a cluster of evaluative feelings about the job. He identified 9 facets of job satisfaction:

1. Pay- salary. amount and fairness or equity of

2. Promotion-opportunities and fairness of promotion.

3. Supervision-fairness and competence at managerial tasks by ones supervisor

4. Benefits- insurance, vacation, and fringe benefits

5. Contingent procedures-sense of respect, recognition and appreciation.

6. Operating procedure-policies, procedures, rules, perceived red tape.

7. Coworkers- perceived competence and pleasantness of ones colleagues.

8. Nature of work- enjoyment of the actual tasks themselves.

9. Communication- sharing information within the organization (verbally or in writing) [5].

Moreover, job satisfaction is directly linked with some organizational phenomena, like hierarchy, supervision. Workers preferred decentralized administration. Participation in decision making can bring job satisfaction. Smith, kendall, and Hulin (1969) have suggested that there are five job dimensions that represents the most important characteristics of a job about which people have affective response. They are -

1. The work itself: the extent to which the job provides the individual with interesting tasks, opportunities for learning, and the chance to accept responsibility

2. Pay: The amount of financial remuneration that is received and the degree to which this is viewed as equitable vis-à-vis that of others in the organization

3. Promotion opportunities: the chances for advancement in the hierarchy

4. Supervision: the abilities of the supervisor to provide technical assistance and behavior support

5. Coworkers: the degree to which fellow workers are technically proficient and socially supportive (Luthans, 1995) [6].

Kotzell (1980) defined Job satisfaction as an employee's satisfaction of his or her job in terms of supervision, co workers, pay, promotions and the work itself. This evaluation is actually a comparison between the employee's expectation about these job related factors and his or her actual experience on the job [7].

Study from the literature of job satisfaction found that there are several factors that may affect employee job satisfaction. These factors are- Payment, working condition, freedom or autonomy, job security, relationship with co-workers, relationship with superior, career advancement and growth, job stress etc. These factors are described below:

Salary

One of the most important factors that affect job satisfaction is salary. Salary should be increased according to the employees' performance. It should be given according to the industry standard and it should be aligned with the present macroeconomic factors.

\section{Working condition}

As employee spends most of the time in an organization, it is essential for organizations to introduce and maintain proper working conditions. It includes physical as well as social environment. Organization should provide its employee's all the necessary resources and update all the information essential to do a job. This will help employees to accomplish tasks successfully and which indeed contribute to job satisfaction.

\section{Freedom or autonomy}

Autonomy refers to the degree of freedom that workers have in their work. It means the level of control employees have timing and scheduling their work activities. 


\section{Job security}

Job security is another very important factor that may affect employee job satisfaction. Employees will often feel more secure if they believe they will not get fired.

\section{Relationship with co-workers}

Every employee seeks to be treated with respect by those they work with. If employees are in touch with supportive colleagues or peer they can do their performance in a better and comfortable way.

\section{Relationship with superior}

Employees need to know their superior's door is always open for them to discuss any issues to do their jobs effectively. Personality, attitude and management skills of superiors affect employees' job satisfaction.

\section{Career advancement or growth}

If employees see a path available to move up the position in the company they would be more satisfied with their existing job. Organization can persuade employees to learn sophisticated skills or to demonstrate them what they need to in order to be on a path to progression inside the organization.

\section{Job Stress}

Stress is a negative reaction towards events that are thought to exceed individual coping ability.

\subsection{Teacher's job satisfaction}

As teachers play the most vital role for the development of a nation, their job satisfaction should be prioritized first. Evans (1998) identified different levels of job satisfaction which indicate some factors of job satisfaction for teacher.

Level I: Policy and condition of service. Pay structure. A well pay structure brings more satisfaction

Level II: Leadership style. (Of head teachers or the senior teachers)

Organizational climate. It includes the pattern of management of the schools, method of accountability of the teachers, level of local people interference, freedom of teachers etc.

Level III: This level suggested determinants of job satisfaction are, typically, individuals needs fulfillment, expectations fulfillment or values congruence. Individual's attitude, norms, values, personality and emotion reflects in this level. [8].

\subsection{Job Satisfaction According to Gender Perspective}

Job satisfaction differs from gender perspective. There is clear distinction between the nature of male defining job satisfaction and female define job satisfaction. The factors affecting the female job satisfaction is working environment, interpersonal relation, and supervision of boss (by the head teacher). For men salary and security of the job is most important. Men more concerned with extrinsic rewards (most notably pay) women focusing more on intrinsic rewards i.e. the satisfaction of teaching children. A large number of female teachers come into this profession willingly. But men often saw teaching as an alternative rather than as the main focus of their career aspiration.

Oshagbemi $(1997,2001)$ has noted that female academics at higher ranks are more satisfied with their jobs than male academics of comparable ranks. Even without considering academic ranks, Oshagbemi (2000) has revealed that female academics are more satisfied with their pay when compared with their male colleagues [9]. On the contrary, less satisfaction of female faculty members than male faculty members is documented by Fiorentino (1999) and Hagedorn (1996, 1998) [10] [11].

Bender and Heywood (2006) have concluded that female academics report lower job satisfaction as compared to their male counterparts [12].

Everyone define job satisfaction as their fulfillment of expectation. It differs from person to person and organization to organization even in context of male and female. So job satisfaction is such phenomenon which comes from not only the job, but also from one's personal, social organizational, administrative and economical condition.

Hence, job satisfaction is the collection of all positive and negative aspects related to individual's salary, working conditions, the rewards, performance and the social environment maintained in relation to his or her job. It refers to an individual subjective experience of his work situations, his response and feeling towards different factors of work role. It is not a unitary concept what a composite of factors or dimensions 


\subsection{Research Design}

\section{Research Design And Methodology}

As this study tries to recognize the factors that affect job satisfaction of teachers of private universities most, the academic members (from different genders, age groups, marital status, education backgrounds, designations) from ten reputed private universities of Bangladesh have been taken as population. Employee Job Satisfaction is taken as dependent variable and it is dependent on some independent factors like- the work itself, payment, career prospect, promotion, supervision, environment and culture. This research was conducted using convenience method of sampling and 72 questionnaires were distributed among the employees. Self designed questionnaire was designed and face to face interview method was used for data collection. While some responded promptly to the survey, others delayed to respond to grasp the questions and enquiries. Nonetheless, most of them were very helpful to fill our questionnaire patiently and some even provided their own personal opinions.

\subsection{Questionnaire Design}

The questionnaire was designed in such a way that would help to understand the job satisfaction level of faculties working in private universities of Bangladesh. To make the questionnaire understandable, it was divided into two parts. The first part of the questionnaire contained questions regarding employee profile which means demographical factors of respondents. The second part of the questionnaire required the respondents to rate various factors that affects job satisfaction into five pre-defined level scale. These scales are as follows: $1=$ Strongly dissatisfied, 2 = Dissatisfied, $3=$ Neutral, $4=$ Satisfied, $5=$ Strongly satisfied.

\subsection{Framework of the Study}

As the study focuses on understanding employee Job satisfaction of the faculties of private universities of Bangladesh, various factors which donate the employee job satisfaction are taken into consideration. These factors came from different studies and include the followings:

[1] Present salary structure

[2] Career Prospect

[3] Physical environment

[4] Relationship with co-workers

[5] Relationship with superiors

[6] Relationship with students

[7] Autonomy or freedom

[8] Job security

[9] Work-life balance

[10] Job stress

\section{Data Analysis And Findings}

People from different background may think of different factors that may enhance their job satisfaction. So, this paper has considered a few important demographic information. Among those- gender, age, years of experience and salary are considered. Respondents' ages lie within 24 to 61 years. Average age is 33.35 years. The demographic characteristics also show a gender division of the respondents, majority of the respondents are females, i.e. $58.33 \%$ representing a larger part of the sample group. However, $41.67 \%$ of the respondents are male. $44.44 \%$ of the employees earned between Tk. 30001 - Tk. 40000. Length of service of most of the respondents $(59.68 \%)$ is between $0-3$ years.

\subsection{Analysis of Job Satisfaction Based on the Response of Teachers of Private Universities}

10 attributes were selected while developing questionnaire to measure job satisfaction of private university faculties. Those attributes are shown in the Table 1. Through the surveyed data, we have understood whether private university faculties are satisfied or not and ranked those attributes according to their level of satisfaction by measuring mean and standard deviation. The analysis of the means and the standard deviations of these variables are depicted in Table 1.

Table-1 Factors Affecting Job Satisfaction of Faculty Members

\begin{tabular}{|l|c|c|c|c|c|c|}
\hline \multicolumn{1}{|c|}{ Factors } & N & Minimum & Maximum & Mean & Std. Deviation & Ranking \\
\hline Present salary structure & 72 & 1 & 5 & 2.6667 & 1.1749 & 10 \\
\hline Career Prospect & 72 & 1 & 5 & 2.8750 & 1.1375 & 9 \\
\hline Physical environment & 72 & 1 & 5 & 3.1805 & 1.0789 & 7 \\
\hline Relationship with co-workers & 72 & 1 & 5 & 4.1111 & 0.6619 & 2 \\
\hline Relationship with superiors & 72 & 1 & 5 & 3.7778 & 0.8756 & 4 \\
\hline Relationship with students & 72 & 1 & 5 & 4.2222 & 0.6329 & 1 \\
\hline
\end{tabular}


Gender Differences in the Domain of Job Satisfaction: A Study on the Private Universities .....

\begin{tabular}{|l|c|c|c|c|c|c|}
\hline Autonomy & 72 & 1 & 5 & 3.8750 & 0.9029 & 3 \\
\hline Job security & 72 & 1 & 5 & 3.7222 & 0.9227 & 5 \\
\hline Work-life balance & 72 & 1 & 5 & 3.500 & 1.0615 & 6 \\
\hline Job Stress & 72 & 1 & 5 & 2.9861 & 1.2044 & 8 \\
\hline
\end{tabular}

\section{Salary}

Payment is the most crucial factor along with some other factors which causes satisfaction of high dissatisfaction to Faculty members. The higher the financial outcome the higher is the satisfaction. This has been found from the response of faculty members of private universities of Bangladesh. From the analysis of the surveyed data, it has been found that private university teachers are not at all satisfied with their present salary structure. Maximum Respondents $(43.06 \%$ ) are dissatisfied with their present salary. Only $26.39 \%$ of the respondents are satisfied with their payment. Others are in neither satisfied nor dissatisfied state. The mean value also complies with this since it shows the lowest score of 2.6667.

So, the study infers that teachers are found dissatisfied because of low salary (ranked 10th among 11 domains). Those who are in lecturer position and holding the position for more than 2 years (Maximum respondents i.e. 44.44\%), their salary lies between Tk. 30000-Tk. 40000. None of the respondent is found satisfied with their existing pay structure. According to Herzberg's two factor theory, salary is a hygiene factor which causes dissatisfaction. If salary is lower the employees become dissatisfied with their jobs. Thus the low or poor salary structure causes dissatisfied almost all the teachers in primary education in Bangladesh.

\section{Career Prospect}

Study also reveals that, maximum number of respondents i.e. 37.05\% are not at all satisfied with their "Career Prospect". Surprising but true, only $36.11 \%$ of the respondents are satisfied with this attribute. The rest of the respondents are neither satisfied nor dissatisfied. The mean value also complies with this by giving the second lowest value of 2.8750 .

So, it is inferred from the study that maximum respondents are not satisfied with their job because there is limited opportunity for career advancement. Delayed promotion is another good reason for dissatisfaction. Management of maximum private universities has little interest to train and develop their employees.

\section{Physical Environment}

In terms of "Physical Environment" maximum (41.67\%) respondents are satisfied. $26.39 \%$ of the respondents are somewhat dissatisfied. The rest of the respondents are in neutral situation. The mean value of this attribute is 3.1805. So, we can conclude that, physical environment (i.e. class room, office room, Computer and lab facilities, toilets, communication, location of the university) of private universities is quite lucrative which satisfies the faculty members.

\section{Social Environment}

Social environment is also another crucial factor for affecting employee job satisfaction. Sound relationship with colleagues, relationship with students, and superiors are the key sub-factor of this attribute which enhances employee satisfaction. According to the survey data, it reveals that, private university teachers have a pleasant relationship with their co-workers, superiors and students. $70.83 \%$ respondents are satisfied with the relationship with their co-workers. $22.22 \%$ of the respondents are highly satisfied with the relationship with colleagues. The mean value also shows significant result (4.1111) which denotes private university teachers are nominating this as second satisfying attribute in the industry.

In terms of "Relationship with superiors" $69.44 \%$ of the respondents are satisfied and $11.11 \%$ of the respondents are highly satisfied. Rests of the respondents are somewhat dissatisfied with their superiors. The mean value for this attribute is 3.7778. According to Linda's (1998) five significant factors regarding to supervision which affects subordinates' job satisfaction; personality, interpersonal behavior, mission, professionalism and management skills. These factors should be remembered by the head teachers.

In terms of "Relationship with Students" $66.67 \%$ of the faculties are satisfied and $29.17 \%$ of the teachers are highly satisfied with the relationship with their students. Rests are in neutral position. The mean value (4.2222, which is the highest score) of this factor shows that private university teachers are in most favorable position with their students.

\section{Freedom or Autonomy}

$50 \%$ of the respondents are satisfied with the "Level of Autonomy" given by management. $23.61 \%$ of the teachers are highly satisfies regarding this issue. And rests are in neither satisfied nor dissatisfied and dissatisfied position. The mean value i.e. 3.8750 indicates this factor as third position in terms of their satisfaction. 
Job Security

The data presented and discussed in earlier sections indicate that the teachers are highly dissatisfied because of low salary, mismanagement in career prospects, gender biased society, job stress etc. Despite of having so many dissatisfactory phenomena, we have asked them a question- "why they have chosen this job". The very common and similar reply from both male and female teachers is job security. Although it is a private job, still job security is higher in this industry. Job security in the sense that the payment is regular, no scope to be fired and financial benefit after retirement is guaranteed.

This factor makes $59.72 \%$ of the respondents highly satisfied. Which reveals this industry gives ample opportunities for the security of the employees' jobs. $13.89 \%$ of the respondents nominating their level of job security as highly satisfying position and only negligible percentage of the respondents are in dissatisfied and neutral position. The mean value of this attribute is 3.7222 .

\section{Work-Life Balance}

Work-life balance is about creating and maintaining supportive and healthy work environments, which will enable employees to have balance between work and personal responsibilities and thus strengthen employee job satisfaction, loyalty and productivity. The present study reveals that, in terms of "Work-Life Balance", $54.17 \%$ of the respondents are satisfied. Which means actually maximum teachers can be able to manage their life with their work loads. Their job is flexible enough to enhance work-life balance. Unfortunately, 5.56\% respondents are highly dissatisfied and $15.28 \%$ of them are dissatisfied. $13.89 \%$ are neither satisfied not dissatisfied with this factor. And rests are highly satisfied. So, it infers that, $65.28 \%$ respondents are in satisfying position with their work-life balance. Rests are not in a good position. This may because of variations in different university's work pressure, flexibility and facilities. Reason for difficulty in managing work-life conflict may also be the respective position the person is holding.

\section{Job Stress}

It is well established fact that employee's job satisfaction and job stress are related to one another (Kahn et al. 1964) [13]. The impact of stress on satisfaction is far more straightforward. Job related stress tends to decrease general job satisfaction (Jackson, 1983) [14]. Finally, in terms of the attribute "Job Stress", study shows that, $44.44 \%$ of the respondents are facing reasonable job stress which makes them satisfied at this point and only $4.17 \%$ respondents are highly satisfied since they do not have to face any job stress. $26.39 \%$ of them are dissatisfied and $13.18 \%$ are highly dissatisfied as they find their job very stressful. Rests are in neutral position. The mean value (i.e.2.986) also proves the actual scenario of the private university faculties of Bangladesh, that the half portion of the respondents are facing job stress. Study also found that, maximum private universities unduly imposed extra clerical workloads as well as academic activities which enhance job stress.

\subsection{A Comparative Study of Job Satisfaction between Male and Female Faculty Members}

As shown in Table 2, the level of job satisfaction among male academic members $(\mathrm{M}=3.47, \mathrm{SD}=$ $1.14)$ and female academic members $(\mathrm{M}=3.52, \mathrm{SD}=0.99)$ were found in this study. This finding recognized that female faculty members were more satisfied than their counterparts.

A comparative analysis regarding different attributes that affect employee job satisfaction has been done between male and female faculties based on the average scores of the each group. This study has found several cases, where both groups have lowest satisfaction. These attributes are- Payment (ranked 9th), Career Prospect (ranked 8th), Physical environment (ranked 7th) and work-life balance (ranked 6th) respectively. The findings of Table 2 also indicated that both male and female faculty of private universities had same level of job satisfaction toward various factors like relationship with students (ranked 1st) and co-workers (ranked 2nd). Which denotes the social environment of private universities is extremely good.

Both of the counterparts had different level of satisfaction toward several other factors. Male counterparts were more satisfied with their superiors (ranked 3rd) than their female counterparts (ranked 5th). Female teachers found that they are not getting positive support from the head teacher which they desire. Study also found that female employees get lower recognition and appreciation than their male counterparts by their supervisors.

They also had quite higher satisfaction with job stress (ranked 7th) than the female counterparts (ranked 8th). However, study shows female faculty members felt that they have much freedom regarding their work (ranked 3rd) and their job is much secured (ranked 4th) which is higher than the male counterpart (ranked 4 th and 5th respectively). 
Gender Differences in the Domain of Job Satisfaction: A Study on the Private Universities .....

Table-2 Comparative Ranking of Job Dimensions between Male and Female Faculty Members

\begin{tabular}{|c|c|c|c|c|c|c|}
\hline \multirow[t]{2}{*}{ Factors } & \multicolumn{2}{|l|}{ Male } & \multicolumn{2}{|l|}{ Female } & \multicolumn{2}{|c|}{ Ranking } \\
\hline & $\mathrm{M}$ & SD & $\mathrm{M}$ & SD & Male & Female \\
\hline $\begin{array}{ll}\text { Overall } & \text { Job } \\
\text { Satisfaction } & \end{array}$ & 3.4667 & 1.1366 & 3.5238 & 0.9936 & & \\
\hline $\begin{array}{ll}\text { Present } & \text { salary } \\
\text { structure } & \end{array}$ & 2.5333 & 1.1366 & 2.7619 & 1.2059 & 9 & 9 \\
\hline Career Prospect & 2.8667 & 1.1059 & 2.8809 & 1.1729 & 8 & 8 \\
\hline $\begin{array}{l}\text { Physical } \\
\text { environment }\end{array}$ & 3.1333 & 1.1059 & 3.2143 & 1.0715 & 7 & 7 \\
\hline $\begin{array}{l}\text { Relationship with } \\
\text { co-workers }\end{array}$ & 4.0 & 0.6948 & 4.1905 & 0.6339 & 2 & 2 \\
\hline $\begin{array}{l}\text { Relationship with } \\
\text { superiors }\end{array}$ & 3.8333 & 0.7466 & 3.7381 & 0.9642 & 3 & 5 \\
\hline $\begin{array}{l}\text { Relationship with } \\
\text { students }\end{array}$ & 4.2 & 0.7916 & 4.2381 & 0.4844 & 1 & 1 \\
\hline Autonomy & 3.7667 & 1.0726 & 3.9524 & 0.7636 & 4 & 3 \\
\hline Job security & 3.6333 & 1.0662 & 3.7857 & 0.8126 & 5 & 4 \\
\hline Work-life balance & 3.5667 & 1.0400 & 3.4524 & 1.0865 & 6 & 6 \\
\hline Job Stress & 3.1333 & 1.1958 & 2.8809 & 1.2138 & 7 & 8 \\
\hline
\end{tabular}

\subsection{Impact of Job Satisfaction on Quality of Education}

The respondents have been asked whether they think that job satisfaction has positive impact on the quality of education or dissatisfaction may cause demoralizing impact on the excellence in education. Maximum respondents (i.e.55\%) felt that job dissatisfaction my cause negative outcomes. Their delivery of lectures may be disrupted and their overall performance might decrease. $30 \%$ of them opined that, of course job satisfaction has positive impact on the quality of education but they did not feel that because of dissatisfaction their normal delivery of lectures and urge of enlightening their students would hamper. Rests of the respondents (only 15\%) think that it is their duty to share knowledge to their students. So they opined that job dissatisfaction would not cause negative impact on quality of education.

\section{Recommendation And Conclusion}

In Bangladesh teaching is one of the honorable professions. This profession is not an exception regarding employee job satisfaction. Job satisfaction of academic members is important for improvement, efficiency and effectiveness of the upper higher education sector. But enhancing satisfaction of these resources is one the major challenges faced by many universities.

Despite a large body of literature, no consensus has been reached on gender differences in job satisfaction. Clark's (1997) seminal study of job satisfaction and gender reveals that gender differences in job satisfaction disappear for the young and the highly educated [13]. Since then a number of papers on gender job satisfaction have been published, however, the findings from these papers are inconclusive. While many papers support Clark's (1997) findings, others reveal the existence of gender job satisfaction gap in both directions. This paper also revealed less significant difference in the level of job satisfaction between male and female counterparts of academic members. However it finds some important factors those should be carefully observed by the educational institutions.

The results from the study revealed that Bangladeshi private universities are performing quite better in enhancing job satisfaction of the teachers. Though some point of disappointments has been revealed through this study. Some factors those need to be considered are-

- Job satisfaction has a remarkable impact on the quality of education. Dissatisfaction may cause devastating effect on education. So, educational institutes must try their fullest to enhance job satisfaction among their teachers.

- Male domination is evidenced in the results of the study which indicated that male faculty were older, had more years of experience in their current position, and had more years of experience in higher education than their female counterparts. Efforts to increase gender diversity among faculty must continue. 
- Female faculty members were more satisfied with their jobs than male faculty in the current study, which implies that there may be some systems in place which fail to take into consideration the perceptions of male faculty members. It should also be considered that females have family considerations which insist them to satisfy with minimum facility.

- Both male and female faculty members were not at all satisfied with their present salary. Teacher's achievements must be rewarded at every cost. Their achievements should be rewarded both intrinsically and extrinsically. A range of salary must have the capability to meet up one's basic need in life. When one's salary cannot meet up that, they have to look for other earning source which decreases quality of education

- The career structure of the teachers should be such that they may get rapid promotions which may be tagged with their teaching performance and research work rather than on their personal characteristics. The promotion should be related to their creative advancement and academic pursuits.

- Efforts should be made to help them develop and those who have improved their qualifications should be properly rewarded. This could enhance the job satisfaction of teachers.

- Both male and female teachers remarked that head teachers' role is an important factor in context of job satisfaction. But male counterparts were more satisfied with their superiors than female counterparts. Female teachers are not getting positive support and flexibility from their superiors for which they have chosen this profession. They desire a participatory, democratic and cooperative supervisor. The superiors must recognize and appreciate the contribution of faculty members and there should not be any discrimination or biasness.

- Management of the private universities should provide abundant research scope to its faculty member if universities want more qualified workforce.

- Female teachers were facing more job stress than their male counterparts. So, job stress should be reduced and clerical academic tasks should not be given to the faculty members.

From this study it can be inferred that there is no significant difference between male and female faculty members' job satisfaction. The slight differences occur because of the Masculine culture and the family responsibility that has to be taken by the female counterparts. The revealed information regarding teachers' payment, career prospect, job stress and physical environment should be carefully considered since job satisfaction depends on all these factors. And a teacher's job satisfaction may have vital impact on quality of education.

It is hoped that the barrier to the job satisfaction of academic members are found in this study may be useful for management institutes to develop work environment and culture that would allow higher levels of faculty job satisfaction and can contribute to a great extent to improve the level of academic members in developing countries like Bangladesh.

There are certain limitations of the study which can be taken into account for further studies in the future, like sample size was too small and only private university in general was considered.

\section{References}

[1]. Robbins, Stephen P. \& Judge, Tim. (2005). Organizational Behavior . Upper saddle River: Prentice-Hall.

[2]. Locke, E.A. (1976). The nature and cause of job satisfaction. In M. D. Dunnette (ed.). Handbook of Industrial and Organizational Psychology. Chicago: Rand McNally.

[3]. Armstrong, M. (2003). A Handbook of Human Resource Management Practice. (9th ed.). London: Kogan Page.

[4]. Hodson.(1991). Advanced Education Psychology. New Delhi: Prentice Hall of India (Private) Ltd.

[5]. Spector, P. E. (2000). Industrial \& organizational psychology, (2nd ed.) New York: John Wiley \& Sons.

[6]. Luthans, Fred (1995): Organizational Behaviour, McGraw Hill, New York.

[7]. Kotzell (1980). A study of mental health in relation to job satisfaction of Navodya Vidyalaya Teachers.

[8]. Evans, Linda, (1998). Teachers Morale, Job Satisfaction and Motivation.

[9]. Oshagbemi, T. (1997). The Influence of Rank on the Job Satisfaction of Organizational Members, Journal of Managerial Psychology. 12: 511-519.

[10]. Mora, T. and A. Ferrer-i-Carbonell (2009). The Job Satisfaction Gender Gap Among Young Recent University Graduates: Evidence from Catalonia, The Journal of Socio-Economics. 38 (4): 581-589.

[11]. Hagedorn, L.S (1998). Implications to Postsecondary Faculty of Alternative Calculation Methods of Gender-based Wage Differentials, Research in Higher Education. 39: 143-162.

[12]. Bender, K.A. and J. S. Heywood (2006). Job Satisfaction of the Highly Educated: The Role of Gender, Academic Tenure and Earnings, Scottish Journal of Political Economy. 53: 253-279.

[13]. Kahn R.L et al. (1964) organizational stress (New York; Wiley)

[14]. Jackson S.E (1983), "Participation in Decision making as a strategy for reducing job-related strain, "Journal of applied Psychology, pp. 3-19.

[15]. Clark, A. E. (1997). Job Satisfaction and Gender: Why are Women So Happy in Work?, Labour Economics. 4: $341-372$.

\section{Appendix}

Personal profile of the respondents $(\mathrm{N}=72)$

\begin{tabular}{|l|l|l|l|l|}
\hline Profile & Frequency & Percentage & Valid Percentage & Cumulative \\
\hline
\end{tabular}


Gender Differences in the Domain of Job Satisfaction: A Study on the Private Universities .....

\begin{tabular}{|c|c|c|c|c|}
\hline & & & & Percentage \\
\hline \multicolumn{5}{|l|}{ Gender } \\
\hline Male & 30 & 41.67 & 41.67 & 41.67 \\
\hline Female & 42 & 58.33 & 58.33 & 100.00 \\
\hline \multicolumn{5}{|l|}{ Age } \\
\hline 24-30 Years & 40 & 55.55 & 55.55 & 55.55 \\
\hline 31-35 Years & 22 & 30.56 & 30.56 & 86.11 \\
\hline $36-40$ Years & 01 & 1.39 & 1.39 & 87.5 \\
\hline 41Years or above & 09 & 12.5 & 12.5 & 100.00 \\
\hline \multicolumn{5}{|c|}{ Years of Experience } \\
\hline $0-3$ Years & 37 & 51.39 & 51.39 & 51.39 \\
\hline 3-6 Y ears & 19 & 26.39 & 26.39 & 77.78 \\
\hline 6-10 Years & 10 & 13.89 & 13.89 & 91.67 \\
\hline 10 Years or above & 06 & 8.33 & 8.33 & 100.00 \\
\hline \multicolumn{5}{|l|}{ Salary in BDT } \\
\hline $20001-30000$ & 11 & 15.28 & 15.28 & 15.28 \\
\hline $30001-40000$ & 32 & 44.44 & 44.44 & 59.72 \\
\hline $40001-500001$ & 21 & 29.17 & 29.17 & 88.89 \\
\hline 50001 or Above & 8 & 11.11 & 11.11 & 100.00 \\
\hline
\end{tabular}

